\title{
Hubungan Komunikasi Terapeutik Perawat dengan Tingkat Kecemasan Hospitalisasi pada Anak Usia Prasekolah (3-6 Tahun)
}

\author{
Vivin Fitriya Febrianti, Lilla Maria, Rahmawati Maulidia \\ Prodi Sarjana Keperawatan, STIKes Maharani, Malang, Indonesia \\ Email korespondensi: vivinfitriya@ gmail.co.id
}

\begin{abstract}
Introduction: Pain and hospitalization create a crisis for the lives of children because in hospitals children have to face a strange environment and meet caregivers whom they do not know. In this process, the child can experience various events or experiences hospitalization that are traumatic and full of anxiety. Professional nurses can play a role in reducing feelings of fear, anxiety and pain that are felt by the children through services using therapeutic communication. The purpose of this study determined the correlation between therapeutic communication of nurses and the anxiety levels of hospitalized preschoolers age children. Method: The study used correlational analysis with a crosssectional approach. The population are 67 parents with children who experienced hospitalization with purposive sampling as the sampling technique. Results: The results of this study were nearly half the nurses had deficient therapeutic communication (44.8\%) and almost half of the patients had severe anxiety levels (44.8\%). The results of the Spearman test showed $\left(r_{\text {count }}\right)$ was $-0,904$ and $p$ value of 0,000 , thus it can be concluded that there was a significant correlation between nurses' therapeutic communication with the anxiety levels of hospitalized children. Conclusions From this study, it is expected that nurses can their improve therapeutic communication skills in providing nursing services through therapeutic communication training programs.
\end{abstract}

Keywords: Therapeutic Communication, Nurses, Anxiety Level, Hospitalization, Preschool Children

\begin{abstract}
Abstrak
Pendahuluan: Sakit dan hospitalisasi menimbulkan krisis bagi kehidupan anak karena di rumah sakit anak harus menghadapi lingkungan yang asing dan bertemu pemberi asuhan yang mereka tidak kenal. Dalam proses tersebut anak dapat mengalami berbagai kejadian atau pengalaman hospitalisasi yang traumatik dan penuh dengan kecemasan. Perawat professional dapat berperan dalam mengurangi perasaan takut, cemas dan nyeri yang dirasakan oleh anak melalui pelayanan dengan menggunakan komunikasi terapeutik. Tujuan dari penelitian ini adalah untuk mengetahui hubungan komunikasi terapeutik perawat dengan tingkat kecemasan anak usia prasekolah. Metode: Desain penelitian menggunakan analisis korelasional dengan pendekatan croos-sectional. Populasi adalah orang tua dengan anak yang mengalami hospitalisasi sejumlah 67 responden dengan teknik sampling menggunakan purposive sampling. Hasil: Hasil penelitian ini hampir setengah perawat memiliki komunikasi terapeutik yang kurang baik yaitu (44.8 \%) dan hampir setengah pasien anak mengalami tingkat kecemasan berat yaitu (44.8 \%). Dari hasil uji Spearman didapatkan ( $\mathrm{r}_{\text {hitung }}$ ) sebesar -0.904 dan nilai p 0.000. Kesimpulan: terdapat hubungan yang signifikan antara komunikasi terapeutik perawat dengan tingkat kecemasan hospitalisasi pada anak. Penelitian ini diharapkan agar perawat dapat
\end{abstract}

Febrianti, F.V., dkk., Hubungan Komunikasi Terapeutik Perawat 


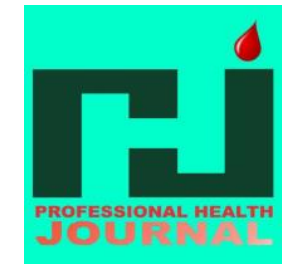

\section{PROFESIONAL HEALTH JOURNAL}

Volume 1, No. 2, Juni 2020 (Hal. 50-57)

Available Online at https:// https://www.ojsstikesbanyuwangi.com

meningkatkan kemampuan komunikasi terapeutik dalam memberikan pelayanan keperawatan melalui program pelatihan komunikasi terapeutik.

Kata kunci: Komunikasi Terapeutik, Perawat, Tingkat Kecemasan, Hospitalisasi, Anak Usia Prasekolah

\section{PENDAHULUAN}

Anak merupakan individu yang masih bergantung pada orang dewasa dan lingkungannya, artinya membutuhkan lingkungan yang dapat memfasilitasi dalam pemenuhan kebutuhan anak untuk pertumbuhan dan perkembangan anak. (Supartini, 2012).

Anak yang mengalami hospitalisasi akan mengalami reaksi sedih, takut, dan bersalah karena menghadapi sesuatu yang belum pernah dialami sebelumnya, rasa tidak aman dan nyaman, perasaan kehilangan yang dialami dan sesuatu yang dirasakan menyakitkan (Naviati, 2011). Berdasarkan survei dari WHO pada tahun 2008, hampir $80 \%$ anak mengalami perawatan di rumah sakit. Sedangkan di Indonesia sendiri berdasarkan survei kesehatan ibu dan anak tahun 2010 didapatkan hasil bahwa dari 1.425 anak mengalami dampak hospitalisasi, dan $33,2 \%$ diantaranya mengalami dampak hospitalisasi berat, $41,6 \%$ mengalami dampak hospitalisasi sedang, dan 25,2\% mengalami dampak hospitalisasi ringan (Rahma \& Puspasari, 2010).

Berdasarkan Survey Ekonomi Nasional (SUSENAS) tahun 2010, jumlah anak usia prasekolah (3-6 tahun) sebesar $72 \%$ dari total penduduk Indonesia. Angka kesakitan anak di Indonesia yang dirawat di rumah sakit cukup tinggi yaitu sekitar 35 per 100 anak. Hal ini ditunjukkan dengan selalu penuhnya ruangan anak baik rumah sakit pemerintah ataupun rumah sakit swasta dan $45 \%$ diantaranya mengalami kecemasan (Sumaryoko, 2008).
Menurut penelitian yang dilakukan oleh Hannan, Susilo, dan Suwanti (2009) di RSUD Ambarawa menunjukkan pelaksanaan komunikasi terapeutik perawat pada anak usia prasekolah di ruang perawatan anak RSUD Ambarawa dapat menurunkan tingkat kecemasan. Ditunjukkan dengan 17 dari 32 responden pasien anak usia prasekolah $(53,1 \%)$ memiliki tingkat kecemasan ringan.

Komunikasi terapeutik merupakan komunikasi yang mempunyai efek penyembuhan karena komunikasi terapeutik merupakan salah satu cara untuk memberikan informasi yang akurat dan membina hubungan saling percaya terhadap klien, sehingga klien akan merasa puas dengan pelayanan yang diterimanya. Apabila perawat dalam berinteraksi dengan klien tidak memperhatikan sikap dan teknik dalam komunikasi terapeutik dengan benar dan tidak berusaha untuk menghadirkan diri secara fisik yang dapat memfasilitasi komunikasi terapeutik, maka hubungan yang baik antara perawat dengan klien pun akan sulit terbina (Anggraini, 2009).

Berdasarkan studi pendahuluan di Rumah Sakit Permata Bunda Malang pada hari Sabtu tanggal 13 Oktober 2018, dengan melakukan wawancara kepada orangtua anak yang sedang menjalani perawatan di Rumah Sakit Permata Bunda Malang, dari 10 orang tua 4 diantaranya

mengatakan bahwa perawat berkomunikasi baik, bersikap ramah, selalu dapat mengalihkan kecemasan anak ketika anak akan dilakukan tindakan invasif, selalu tersenyum kepada anak maupun keluarga, 


\section{PROFESIONAL HEALTH JOURNAL}

Volume 1, No. 2, Juni 2020 (Hal. 50-57)

Available Online at https:// https://www.ojsstikesbanyuwangi.com

dan menanyakan keadaan atau perkembangan anak, sedangkan 6 diantaranya mengatakan bahwa perawat belum melakukan komunikasi yang baik kepada anak yang mengalami hospitalisasi terutama sebelum melakukan prosedur tindakan kepada anak. Dan berdasarkan kecemasan anak, dari 10 orangtua 8 diantaranya mengatakan anaknya rewel menangis terus, tidak mau berinteraksi dengan orang lain, dan terus merengek minta pulang sedangkan 2 orangtua mengatakan anaknya tidak rewel namun cenderung murung. Maka peneliti tertarik untuk melakukan penelitian "Hubungan komunikasi terapeutik perawat dengan tingkat kecemasan hospitalisasi anak usia prasekolah (3-6 tahun) di Rumah Sakit Permata Bunda Malang" dengan tujuan untuk mengetahui hubungan antara komunikasi terapeutik perawat dengan tingkat kecemasan hospitalisasi anak usia prasekolah (3-6 tahun) di Rumah Sakit Permata Bunda Malang.

\section{METODE}

Penelitian ini merupakan penelitian lapangan yang dilaksanakan dengan menggunakan metode analisis korelasional dengan menggunakan pendekatan cross sectional. Penelitian dilakukan pada orang tua dengan anak yang mengalami hospitalisasi di Rumah Sakit Permata Bunda Malang berjumlah 67 responden yang memenuhi kriteria inkluasi dan eksklusi. Instrumen dalam penelitian ini adalah menggunakan alat ukur kuesioner.

Cara pengambilan sampel pada penelitian ini menggunakan purposive sampling. Purposive sampling adalah suatu teknik penetapan sampel dengan cara memilih sampel di antara populasi sesuai dengan yang dikehendaki peneliti (tujuan/masalah dalam penelitian) (Nursalam, 2017).

Febrianti, F.V., dkk., Hubungan Komunikasi Terapeutik Perawat
Variabel Independen (bebas) dalam penelitian ini adalah komunikasi terapeutik. Sedangkan Variabel Dependen (terikat) dalam penelitian ini adalah Tingkat Kecemasan Hospitalisasi Pada Anak.

Etika Penelitian ini diajukan ke STIKes Maharani Malang dengan No.012/KEPK.SM-EC/V/2019 dan di nyatakan Layak Etik pada tanggal $24 \mathrm{Mei}$ 2019.

\section{HASIL}

Tabel 1. Tabel Karakteristik berdasarkan data umum

\begin{tabular}{|c|c|c|c|}
\hline Keterangan & Kategori & $\mathbf{F}$ & $\%$ \\
\hline \multirow[t]{2}{*}{ Hubungan Dengan Pasien } & Ayah & 0 & 0 \\
\hline & Ibu & 67 & 100 \\
\hline \multirow[t]{4}{*}{ Umur Anak } & 3 Tahun & 23 & 34.3 \\
\hline & 4 Tahun & 15 & 22.4 \\
\hline & 5 Tahun & 13 & 19.4 \\
\hline & 6 Tahun & 16 & 23.9 \\
\hline \multirow[t]{3}{*}{ Anak $\mathrm{Ke}$} & 1 & 37 & 55.2 \\
\hline & 2 & 26 & 38.8 \\
\hline & 3 & 4 & 6.0 \\
\hline \multirow[t]{2}{*}{ Jenis Kelamin } & Laki laki & 32 & 47.8 \\
\hline & Perempuan & 35 & 52.2 \\
\hline \multirow[t]{4}{*}{ Lama Rawat Inap } & $1 \mathrm{Han}$ & 1 & 1.5 \\
\hline & $2 \mathrm{Han}$ & 59 & 88.1 \\
\hline & $3 \mathrm{Han}$ & 5 & 7.5 \\
\hline & $>4$ Han & 2 & 3.0 \\
\hline \multirow{4}{*}{$\begin{array}{lll}\text { Pengalaman } & \text { Masuk Rumah } \\
\text { Sakit } & & \end{array}$} & Tidak & 41 & 61.2 \\
\hline & Pemah & & \\
\hline & Sudah & 26 & 38.8 \\
\hline & Pemah & & \\
\hline
\end{tabular}

Berdasarkan tabel diatas, dari 67 responden didapatkan hasil bahwa seluruh responden memiliki hubungan dengan pasien adalah sebagai ibu (100\%). Sebagian besar usia pasien anak 3 tahun sebanyak 23 pasien (34.3\%), sedangkan sebagian kecil pasien anak berusia 5 tahun sebanyak 13 pasien (19.4\%). Sebagian besar pasien anak adalah anak ke 1 sebanyak 37 pasien (55.2\%), sedangkan sebagian kecil pasien anak ke 3 sebanyak 4 pasien $(6,0 \%)$. Jenis Kelamin sebagian besar adalah perempuan sebanyak 35 pasien (52.2\%), sebagian kecil adalah laki laki sebanyak 32 pasien (47.8\%). Hampir seluruh pasien anak telah dirawat inap selama 2 hari sebanyak 59 pasien $(88.1 \%)$, 


\section{PROFESIONAL HEALTH JOURNAL}

Volume 1, No. 2, Juni 2020 (Hal. 50-57) Available Online at https:// https://www.ojsstikesbanyuwangi.com

sedangkan sebagian kecil telah dirawat inap 1 hari sebanyak 1 pasien $(1.5 \%)$. Sebagian besar pasien anak tidak pernah dirawat di rumah sakit sebanyak 41 pasien $(61.2 \%)$, sedangkan sebagian kecil pasien anak sudah pernah dirawat di rumah sakit sebanyak 26 pasien $(38.8 \%)$.

Tabel 2. Tabel Karakteristik berdasarkan Komunikasi Terapeutik Perawat

\begin{tabular}{lcc}
\hline $\begin{array}{c}\text { Komunikasi } \\
\text { Terapeutik }\end{array}$ & Frekuensi & $\begin{array}{c}\text { Prosentase } \\
\%\end{array}$ \\
\hline Tidak Baik & 11 & 16.4 \\
Kurang Baik & 30 & 44.8 \\
Baik & 24 & 35.8 \\
Sangat Baik & 2 & 3.0 \\
\hline Total & 67 & 100 \\
\hline
\end{tabular}

Berdasarkan data tabel diatas dapat diketahui dari 67 perawat didapatkan bahwa sebagian besar perawat memiliki komunikasi terapeutik yang kurang baik yaitu 30 perawat (44.8\%), sedangkan sebagian kecil perawat memiliki komunikasi terapeutik yang sangat baik yaitu 2 perawat $(3.0 \%)$.

Tabel 3. Tabel Karakterisitik Berdasarkan Tingkat Kecemasan Hospitalisasi Pada Anak Usia Prasekolah (3-6 Tahun)

\begin{tabular}{lcc}
\hline Keterangan & Frekuensi & $\begin{array}{c}\text { Prosentase } \\
\%\end{array}$ \\
\hline $\begin{array}{l}\text { Kecemasan } \\
\text { Ringan }\end{array}$ & 1 & 1.5 \\
$\begin{array}{l}\text { Kecemasan } \\
\text { Sedang }\end{array}$ & 26 & 38.8 \\
$\begin{array}{l}\text { Kecemasan } \\
\text { Berat }\end{array}$ & 30 & 44.8 \\
Panik & 10 & 14.9 \\
\hline Total & 67 & 100 \\
\hline
\end{tabular}

Berdasarkan data tabel diatas dapat diketahui dari 67 pasien anak didapatkan hasil bahwa sebagian besar pasien anak mengalami kecemasan berat sebanyak 30 pasien (44.8\%), sedangkan sebagian kecil pasien anak mengalami kecemasan ringan sebanyak 1 pasien $(1.5 \%)$.

Tabel 4. Tabel Tabulasi Silang antara Komunikasi Terapeutik Perawat Dengan Tingkat Kecemasan Hospitalisasi Pada Anak Usia Prasekolah (3-6 Tahun)

\begin{tabular}{lllllllllllll}
\hline \multicolumn{11}{c}{ Tingkat Kecemasan Anak } \\
\hline \multirow{3}{*}{ Komunikasi } & Tidak Ban & $\%$ & Sedang & $\%$ & Berat & $\%$ & Panik & $\%$ & Total \\
Terapeutik & 1 & 1.5 & 0 & 0 & 0 & 0 & 10 & 14.9 & 11 & 16.4 \\
Perawat & Kurang Baik & 0 & 0 & 0 & 0 & 30 & 44.8 & 0 & 0 & 30 & 4.8 \\
& Baik & 0 & 0 & 24 & 35.8 & 0 & 0 & 0 & 0 & 24 & 35.8 \\
& Sangat Baik & 0 & 0 & 2 & 3.00 & 0 & 0 & 0 & 0 & 2 & 3.00 \\
Total & & 1 & 1.5 & 26 & 38.8 & 30 & 44.8 & 10 & 14.9 & 67 & 100 \\
\hline
\end{tabular}

Berdasarkan data tabel diatas dapat diketahui bahwa 67 pasien anak sebagian besar memiliki tingkat kecemasan berat sebanyak 30 pasien $(44.8 \%)$ dan komunikasi terapeutik perawat kurang baik. Sedangkan sebagian kecil pasien anak memiliki tingkat kecemasan ringan sebanyak 1 pasien anak (1.5\%) dengan komunikasi terapeutik perawat tidak baik.

Tabel 5. Tabel Hasil Uji Spearmen antara Komunikasi Terapeutik Perawat Dengan Tingkat Kecemasan Hospitalisasi Pada Anak Usia Prasekolah (3-6 Tahun) Di Rumah Sakit Permata Bunda Malang

\begin{tabular}{lcl}
\hline \multicolumn{3}{c}{ Tingkat Kecemasan } \\
\hline $\begin{array}{l}\text { Komunikasi } \\
\text { Terapeutik }\end{array}$ & $\mathrm{r}$ & -0.904 \\
Perawat & $\mathrm{p}$ & 0.000 \\
& $\mathrm{n}$ & 67 \\
\hline
\end{tabular}

Berdasarkan hasil uji korelasi spearman pada tabel diatas didapatkan nilai koefisiensi korelasi spearman ( $\mathrm{r}$ hitung) sebesar -0.904 dengan p-value 0.000 . kurang dari $\alpha=0.05$. Hal ini menunjukkan bahwa terdapat korelasi antara komunikasi terapeutik perawat dengan tingkat kecemasan hospitalisasi pada anak. Koefisien korelasi spearman yang berbentuk sebesar -0.904 yang berarti hubungan antara komunikasi terapeutik perawat dengan tingkat kecemasan hospitalisasi anak bersifat negatif atau 


\section{PROFESIONAL HEALTH JOURNAL}

Volume 1, No. 2, Juni 2020 (Hal. 50-57)

Available Online at https:// https://www.ojsstikesbanyuwangi.com

berlawanan arah dan memiliki kekuatan hubungan sangat kuat. Apabila komunikasi terapeutik perawat semakin baik maka tingkat kecemasan hospitalisasi pada anak semakin turun, demikian pula jika sebaliknya.

\section{PEMBAHASAN}

Berdasarkan data tabel diatas dapat diketahui bahwa 67 pasien anak sebagian besar memiliki tingkat kecemasan berat sebanyak 30 pasien $(44.8 \%)$ dan komunikasi terapeutik perawat kurang baik. Sedangkan sebagian kecil pasien anak memiliki tingkat kecemasan ringan sebanyak 1 pasien anak (1.5\%) dengan komunikasi terapeutik perawat tidak baik.

Hal tersebut dikarenakan anak telah memiliki pengalaman di rawat di Rumah Sakit sehingga anak sudah mengenal lingkungan Rumah Sakit. Sedangkan kecemasan berat di dapatkan sebanyak 30 pasien dengan komunikasi terapeutik kurang baik. Kecemasan berat ini banyak dialami dalam segi psikologis seperti anak yang takut, cemas, dan khawatir terhadap tindakan di Rumah Sakit serta lingkungan Rumah Sakit yang tidak nyaman.

Hasil penelitian tersebut didukung dengan teori (Ramdaniati, 2011) jika anak mengganggap pengalaman dilakukan tindakan invasif bukanlah suatu pengalaman yang mengancam tetapi pengalaman yang menyenangkan, anak akan lebih kooperatif pada perawat maupun dokter. Jika pengalaman tersebut merupakan pengalaman yang tidak menyenangkan akan menyebabkan anak trauma dan mengembangkan koping yang tidak adaptif.

Berdasarkan hasil uji statistik dengan menggunakan korelasi Spearman Rank kemudian dianalisis dengan menggunakan fasilitas komputer program SPSS versi 16 dengan nilai $r$ sebesar -
0.904 yang berarti hubungan antara komunikasi terapeutik perawat dengan tingkat kecemasan hospitalisasi anak bersifat negatif atau berlawanan arah dan memiliki kekuatan hubungan sangat kuat dan nilai $p$ sebesar $0.000(\alpha<0,005)$. Hal ini menunjukan bahwa hipotesis yang diajukan diterima, yaitu Ho ditolak dan $\mathrm{H} 1$ diterima. Berdasarkan kriteria uji tersebut maka dapat disimpulkan terdapat hubungan antara komunikasi terapeutik perawat dengan tingkat kecemasan hospitalisasi pada anak usia prasekolah (36 tahun) di rumah sakit permata bunda malang.

Pelaksanaan komunikasi terapeutik bertujuan membantu pasien menjelaskan dan mengurangi beban pikiran, perasaan, mengurangi keraguan dan mempercepat interaksi kedua pihak antara perawat dan pasien sehingga dapat membantu dilakukannya tindakan yang efisen (Marfoedz, 2009). Komunikasi perawat di rumah sakit juga bertujuan agar pelayanan keperawatan yang diberikan berjalan efektif.

Intervensi yang penting dilakukan perawat yang merawat pasien anak dirumah sakit pada prinsipnya untuk meminimalkan stresor, mencegah perasaan kehilangan, meminimalkan rasa takut terhadap perlukaan dan nyeri serta memaksimalkan manfaat perawatan di rumah sakit. Terapi komunikasi terapeutik juga merupakan salah satu cara yang efektif dalam mengatasi kecemasan pada anak yang dirawat di rumah sakit. Hubungan perawat dengan pasien yang terapeutik dapat memberikan pengalaman perbaikan emosi bagi pasien. Hal ini menyebabkan perawat mengaplikasikan dirinya secara terapeutik dan memakai berbagai teknik komunikasi agar perilaku pasien berubah ke arah yang positif (Dalawi, E.Rochimah, Gustina, Roselina, E. Banon, 2009). 
Maka dari hasil penelitian ini dapat disimpulkan bahwa semakin baik komunikasi terapeutik yang dilakukan perawat maka semakin turun tingkat kecemasan hospitalisasi pada anak. Sebaliknya jika komunikasi terapeutik perawat dilakukan kurang baik maka akan menyebabkan tingginya tingkat kecemasan yang terjadi pada anak. Dukungan keluarga juga berperan penting dalam tingkat kecemasan pada anak. Anak akan merasa aman jika berada didekat orang-orang yang dia sayangi.

\section{KESIMPULAN}

a. Dari seluruh pasien anak hampir setengahnya sebanyak 30 pasien anak dengan tingkat kecemasan berat yaitu (44.8\%).

b. Dari seluruh perawat hampir setengah perawat sebanyak 30 perawat memiliki komunikasi terapeutik yang kurang baik yaitu $(44.8 \%)$.

c. Adanya hubungan antara komunikasi terapeutik perawat dengan tingkat kecemasan hospitalisasi pada anak usia prasekolah (3-6 tahun) di rumah sakit permata bunda malang.

\section{SARAN}

a. Bagi Perawat

Penelitian ini dapat menjadi suatu

informasi tentang hubungan komunikasi terapeutik perawat dengan tingkat kecemasan hospitalisasi anak usia prasekolah serta meningkatkan kemampuan komunikasi terapeutik perawat dalam memberikan pelayanan keperawatan.

b. Bagi Rumah Sakit

Sebagai bahan masukan bagi rumah sakit dalam rangka meningkatkan mutu pelayanan, khususnya tentang komunikasi perawat dengan tingkat

\section{PROFESIONAL HEALTH JOURNAL}

Volume 1, No. 2, Juni 2020 (Hal. 50-57)

https:// https://www.ojsstikesbanyuwangi.com 


\section{PROFESIONAL HEALTH JOURNAL}

Volume 1, No. 2, Juni 2020 (Hal. 50-57)

Available Online at https:// https://www.ojsstikesbanyuwangi.com

Dahlan, Sopiyudin M. 2013. Besar Sampel dan Cara Pengambilan Sampel. Jakarta: Salemba Medika

Gunarsa, S. D. 2011. Psikologi Perkembangan Anak dan Remaja. Jakarta: BPK. Gunung Mulia

Hidayat, A. A. A. (2009). Pengantar Ilmu Kesehatan Anak. Jakarta: Salemba Medika.

Machfoedz I, et al. 2009. Metodologi Penelitian Bidang Kesehatan, Keperawatan, Kebidanan, Kedokteran. Yogyakarta: Fitramaya.

Mubarak, W I dan Chayatin N, 2012, Ilmu Keperawatan Komunitas Pengantar dan Teori. Jakarta: Salemba Medika

Mulyani et al. 2008. Komunikasi dan Hubungan Terapeutik Perawat-Klien terhadap Kecemasan Pra-Bedah Mayor. Yogyakarta; 2008.

Mundakir, 2010, Komunikasi Keperawatan Aplikasi Dalam Pelayanan, Edisi 1

Murwani, A \& Istichomah (2009). Komunikasi Terapeutik Panduan Bagi Perawat Yogyakarta: Fitramaya.

Notoatmodjo, Soekidjo. Ilmu Perilaku Kesehatan. Jakarta. Rineka Cipta. 2012

Nurhasanah, Nunung. (2010). Ilmu Komunikasi Dalam Konteks Keperawatan. Jakarta: TIM

Nursalam. (2013). Konsep dan Penerapan Metodologi Penelitian Ilmu Keperawatan. Jakarta: Salemba Medika.

Sukarmin, Subiwati. (2014). Hubungan antara lama hospitalisasi dan persepsi keluarga tentang perilaku perawat
Potter, P. A \& Perry, A.G. (2010). Buku Ajar Fundamental Keperawatan. Edisi keempat, Jakarta: EGC.

Potter, P. A.,\& Perry, A. G. (2010). Buku Ajar Fundamental Keperawatan.ed.7 buku 3. Jakarta: Salemba Medika

Ramdaniati, S. 2011. Analisis determinan kejadian takut pada anak pra sekolah dan sekolah yang mengalami hospitalisasi di Ruang Rawat Anak RSU Blud dr. Slamet Garut. Tesis. Universitas Indonesia.

Rahma, F. \& Puspasari, Y. N. (2010). Upaya Meningkatkan Daya Pikir Anak Melalui Permainan Edukatif. Diakses dari

http://etd.eprints.ums.ac.id/9837/1/A52 0085042.pdf.

Severo, Richard. (2009). Play Eases The Fears Of Hospitalized Children. www.nytimes.com diakses pada tanggal 5 maret 2009.

Stuart, G.W \& Sundeen, S.J, 2008. Buku saku keperawatan jiwa edisi 3. Jakarta: EGC.

Survei Kesehatan Nasional (SUSENAS). (2010). Jumlah anak usia prasekolah di indonesia. Diakses dari: http://www.rand.org/labor/bps/susenas. html pada tanggal: 11 november 2015 .

Sugiyono. (2014) Metode Penelitian Pendidikan Pendekatan Kuantitatif, Kualitatif, dan R\&D. Bandung: Alfabeta.

Sujatmiko, Budiman. 2013. Anak - Anak Revolusi. Jakarta: Gramedia dengan kecemasan anak prasekolah di RSU PKU Muhammadiyah Gubug. Jurnal Ilmu Keperawatan dan kebidanan. Vol.8 No.2 (2017) 19-24. 


\section{PROFESIONAL HEALTH JOURNAL}

Volume 1, No. 2, Juni 2020 (Hal. 50-57) Available Online at https:// https://www.ojsstikesbanyuwangi.com

Sumaryoko. (2011) Hubungan Tingkat Pendidikan dengan Tingkat Pengetahuan Perawat tentang Terapi Bermain pada Anak di Rumah Sakit Se Wilayah Boyolali. Skripsi. Universitas Muhammadiyah Surakarta. Publikasi tahun 2012.

Supartini, Y., 2012, Buku Ajar Konsep Keperawatan Anak, EGC, Jakarta.
Widianti, C. R. (2011). Pengaruh senam otak terhadap kecemasan akibat hospitalisasi pada anak usia prasekolah di RS Panti Rapih Yogyakarta. Tesis Fakultas Keperawatan Universitas Indonesia. Publikasi tahun 2012

Wong, L. Donna. 2009. Buku Ajar Keperawatan Pediatrik. Vol. 1. Edisi 6. Jakarta: EGC. 